\title{
Environment Status: Official Assessment vs Perception by the Population
}

\author{
Natalya Dmitrieva ${ }^{1, *}$, Irina Sandrakova ${ }^{1}$, Galina Chistyakova $^{1}$, and Olga Gabinskaya ${ }^{1}$ \\ ${ }^{1}$ Plekhanov Russian University of Economics, Kemerovo Institute (branch), 650992 Kuznetsky Av. \\ 39, Kemerovo, Russia
}

\begin{abstract}
Environmental deterioration is a challenge for all major cities. Public authorities improve environment monitoring systems, develop and implement measures to reduce the negative consequences of manufacturing activities, inform the population. The article analyzes data on the state and dynamics of the environment status in Kemerovo (Western Siberia, Russia), where a large number of manufacturing enterprises are concentrated. The results of Kemerovo population survey aimed at assessment of perception of the air and water pollution degree, the attitude to the influence of meteorological conditions and landscape features on the environment status, and identification of respondents' opinions about the enterprises having the greatest impact on the environment are described. In addition, the survey assessed changes in the environment status and the degree of personal concern of citizens. The results of the survey were compared with statistic data; a number of discrepancies were identified. The authors offer some recommendations for public authorities on working with the population on environmental issues.
\end{abstract}

\section{Introduction}

Environmental pollution is one of the most pressing problems of human civilization. Due to the fact that $1 / 8$ of the world's population dies of air pollution every year, atmospheric poisoning has assumed the status of an environmental disaster. Ecological problems and environment protection are discussed at the World Economic Forum and the Global Environment Fund. However, meeting this challenge requires coordinated actions not only at the international and national level, but also at the regional one.

In the Kemerovo region - Kuzbass (Western Siberia, Russia), the State Program of the Kemerovo Region "Ecology, Subsoil Resources Management and Rational Water Use" is in force. The regional project "Clean Air" adopted in December 2018 aims at reducing the total volume of polluting substances emissions into the air and decreasing the level of air pollution in Novokuznetsk by December 31, 2024. The goal of the regional project "Clean Water" is improving the quality of drinking water for the population, providing the population with high-quality drinking water from central water supply systems to $98.9 \%$ by the end of 2024. In February 2020, the Department of Natural Resources and Ecology created the Public Ecological Council, which will serve as an advisory and expert body in

\footnotetext{
* Corresponding author: dmitrievanv@yandex.ru
} 
developing and evaluating concepts, programmes, and initiatives of citizens, public associations and organizations on the most challenging environmental issues. This body is to closely cooperate with public councils under the heads of municipalities, environment activists, and select the most effective ideas for environment protection and rational use of natural resources.

Kuzbass coal mining enterprises in association with research centers are actively developing and implementing environment protection technologies. Researches aimed at ecological risk management in coal mining and processing [1], ensuring ecological [2-4] and economic security [5-7] of coal mining regions are conducted. The issues of legal [8-9], environmental and socio-economic responsibility [10-12] of coal mining enterprises to the population and the state are given priority. Besides, the international practice of using legislative, economic and administrative measures aimed at establishing a balance between social and economic development and environment conservation in mining regions is taken into consideration [13].

\section{Results and discussion}

The main indicators characterizing the environmental impact of business activities include:

- discharge of polluted wastewater (excluding the volume of storm water discharged into water bodies);

- emissions of air polluting substances from stationary sources;

- amount of captured and neutralized air polluting substances;

- area of disturbed land;

- amount of generated production and consumption wastes;

- use and processing of production and consumption wastes.

The dynamics of the above indicators for the Kemerovo region - Kuzbass is presented in Table 1. The information base used is the official website of the Federal State Statistics Service, Kemerovo Regional Office.

Table 1. The dynamics of the main indicators characterizing the environmental impact of business activities for the Kemerovo region - Kuzbass, percent to previous year.

\begin{tabular}{|c|c|c|c|}
\hline Indicators & $\mathbf{2 0 1 6}$ & $\mathbf{2 0 1 7}$ & $\mathbf{2 0 1 8}$ \\
\hline $\begin{array}{c}\text { discharge of polluted wastewater (excluding } \\
\text { the volume of storm water discharged into } \\
\text { water bodies) }\end{array}$ & 96.1 & 97.5 & 81.9 \\
\hline $\begin{array}{c}\text { emissions of air polluting substances from } \\
\text { stationary sources }\end{array}$ & 100.4 & 110.3 & 93.0 \\
\hline $\begin{array}{c}\text { amount of captured and neutralized air } \\
\text { polluting substances }\end{array}$ & 90.4 & 104.4 & 83.1 \\
\hline $\begin{array}{c}\text { area of disturbed land } \\
\text { amount of generated production and } \\
\text { consumption wastes }\end{array}$ & 102.7 & 105.7 & 105.6 \\
\hline $\begin{array}{c}\text { use and processing of production and } \\
\text { consumption wastes }\end{array}$ & 173.9 & 88.8 & 60.7 \\
\hline
\end{tabular}

The analysis of the data presented has shown that in the period from 2017 to 2018, in Kuzbass, there is a reduction in discharge of polluted wastewater, emissions of air polluting substances from stationary sources, and the area of disturbed lands. At the same time, the amount of captured and neutralized air polluting substances, as well as the use and processing of production and consumption waste, were significantly reduced, that negatively affected the environment status. 
The problem of polluted trade effluents has always been a challenging one for Kuzbass. [14]. According to the Water Resources Department of the Upper Ob Basin Water Directorate for Kuzbass, the volume of recycled and successive water use, including wastewater and collector-drainage water, decreased by $2.2 \%$ in 2018 compared to 2017.

In 2018 , the decrease in the volume of discharge of wastewater with pollutants amounted to $5.3 \%$. Sulfates $(34.3 \%)$, chlorides $(18.6 \%)$ and nitrate anion $(15.9 \%)$ predominate in wastewater. In 2016-2018 the content of substances such as phosphates, phenol and lead did not change and amounted to $0.2 \%, 0.2 \%$ and $0.1 \%$, respectively.

Since 2018, Kuzbass demonstrates a reduction in pollutants released into the atmosphere. Air pollution levels are assessed by means of various techniques, including the integrated instrumental monitoring, calculation, remote sensing, etc. [15]. Based on the data of the Federal Service for State Registration, Cadastre and Cartography, the Kemerovo Region Department, the volume of emissions per inhabitant in 2018 decreased by $6.4 \%$ as compared to that in 2017. At the same time, the amount of captured and neutralized air pollutants declined by $17 \%$, which indicates deterioration in the cleaning of the region's air basin from polluting substances from stationary sources. In 2018 , only $58.8 \%$ of the total amount of air polluting substances captured by treatment plants was utilised. Gaseous and liquid substances $(90 \%)$ predominate in the composition of air emissions. The content of the solids including benzopyrene, the combustion product of liquid hydrocarbon, solid and gaseous fuels, amounts to $10 \%$.

The "Clean Air" regional program, unfortunately, does not address the issue of air pollution in Kemerovo, one of the largest industrial cities in the region. Kemerovo Regional Office of the Federal State Statistics Service states that in 2018 there was a 3\% increase in the number of facilities with stationary sources of emissions in the Kemerovo urban district. However, the amount of pollutants released into the atmosphere decreased by $4.3 \%$ (from 42.957 to 41.106 thousand tons). However, despite the rise in environment protection costs by $46.7 \%$ (from 4,053,882 thousand rubles in 2016 to 5,945,017 thousand rubles in 2018), less than $1.2 \%$ of the total amount of pollutants was captured and neutralized.

Statistics for 2018 shows that there are solids (17.9\%), as well as gaseous and liquid substances $\left(82.1 \%\right.$ ), such as sulfur dioxide, carbon oxide (in terms of $\mathrm{NO}_{2}$ ), nitrogen oxide, hydrocarbons, volatile organic compounds, and others in the atmosphere of the city. The largest amount of pollution is observed for the following substances: sulfur dioxide (43.2\%), nitrogen oxide (29.7\%), and carbon oxide (20.6\%). In 2018 in comparison with 2017 the content of gaseous and liquid substances in the air decreased by $2.3 \%$, including sulfur dioxide by $3.7 \%$, nitrogen oxide by $4.5 \%$. Though, there was an increase of emissions of carbon by $4.5 \%$, hydrocarbons by $19.4 \%$, volatile organic compounds by $7.9 \%$ and other gaseous and liquid substances by $0.6 \%$.

It is worth noting that in 2018 the content of solids (including benzopyrene) in the city atmosphere decreased by $12.6 \%$. The main source of this pollutant in urban air is burning of solid and liquid organic substances, such as coal, oil and oil products (gasoline), wood, and anthropogenic waste. Taking into consideration the increase in the number of cars in the city during this period of time, and consequently the rise in emissions from them, a decrease in emissions from the private sector and energy-generating enterprises can be assumed. Unfortunately, we failed to find the dynamics of these indicators released to the public.

On February 22, 2020, Deputy Governor of Kuzbass for Industry, Transport and Ecology noted that "emissions from energy generating companies, which give us light and heat, and which are difficult to refuse from, together with emissions from the private sector, amount to almost 50\%." Most atmospheric emissions come from motor transport $(31.9 \%)$, energy generating capacities (Kemerovo Hydroelectric Power Plant and New Kemerovo Combined Heat and Power Station, 29.2\%), AO SDS Azot (19.2\%), the private sector 
(14.2\%), PAO Koks (4.8\%), and OOO Khimprom (0.7\%). In our opinion, motor transport (31.9\%) and energy generating capacities $(29.2 \%)$ pollute the city air to a greater extent. Of course, it is impossible to refuse the enterprises that give us light and heat, but it is worth considering the quality of cleaning their emissions.

According to the Deputy Governor, the geographical location of Kemerovo also contributes to the state of the air atmosphere. The city is located within the rugged hilly plain of the north of the Kuznetsk Basin. Kemerovo can be compared with Novokuznetsk (the Kemerovo region) and Minusinsk (the Krasnoyarsk Territory). These cities are in a hollow and have become hostages of their geographical position. However, only the central part of Kemerovo is located in lowland, while smog is observed in other areas of the city too. Therefore, the geographical location of the city, in our opinion, is not worth considering as a significant cause of air pollution.

In order to identify the attitude of Kemerovo population to environmental problems, a sociological survey was conducted. The main tasks of the survey were identified as follow:

- assessment of perception of the air and water pollution degree;

- identification of the main sources of emissions, which, according to the population, cause the greatest damage to the environment status;

- determination of the population attitude to the meteorological conditions and landscape features of Kemerovo as factors affecting the environment status;

- identification of respondents' opinions about the enterprises having the greatest impact on the environment;

- assessment of the environment changes perception and the degree of personal concern.

The population of Kemerovo aged 15 to 64 was considered as the general population. According to the data of the Federal State Statistics Service, Kemerovo Regional Office, as of January 1, 2019, the population of Kemerovo amounted to 396,218 people. The required sample size was 350 people. Based on data on the population structure by the city district, gender and age, quotas were calculated, the sizes of which are presented in Table 2.

Table 2. Sampling structure for a survey of Kemerovo population.

\begin{tabular}{|c|c|c|c|c|c|c|c|c|c|c|}
\hline \multirow{4}{*}{$\begin{array}{l}\text { Age of } \\
\text { respond } \\
\text { ents }\end{array}$} & \multicolumn{10}{|c|}{ Area of residence } \\
\hline & \multicolumn{2}{|c|}{ Zavodskiy } & \multicolumn{2}{|c|}{ Leninskiy } & \multicolumn{2}{|c|}{ Kirovskiy } & \multicolumn{2}{|c|}{ Tsentral'nyy } & \multicolumn{2}{|c|}{ Rudnichnyy } \\
\hline & \multicolumn{2}{|c|}{ gender } & \multicolumn{2}{|c|}{ gender } & \multicolumn{2}{|c|}{ gender } & \multicolumn{2}{|c|}{ gender } & \multicolumn{2}{|c|}{ gender } \\
\hline & male & female & male & female & male & female & male & female & male & female \\
\hline $15-24$ & 7 & 11 & 9 & 12 & 2 & 2 & 7 & 8 & 5 & 5 \\
\hline $25-34$ & 14 & 10 & 11 & 12 & 4 & 4 & 8 & 8 & 7 & 7 \\
\hline $35-44$ & 11 & 11 & 10 & 9 & 4 & 4 & 9 & 8 & 5 & 5 \\
\hline $45-54$ & 9 & 11 & 7 & 10 & 2 & 3 & 6 & 7 & 5 & 6 \\
\hline $55-64$ & 7 & 10 & 6 & 10 & 2 & 3 & 4 & 5 & 3 & 5 \\
\hline Total & 48 & 53 & 43 & 53 & 14 & 16 & 34 & 36 & 25 & 28 \\
\hline TOTAL & \multicolumn{2}{|c|}{101} & \multicolumn{2}{|c|}{96} & \multicolumn{2}{|c|}{30} & \multicolumn{2}{|c|}{70} & \multicolumn{2}{|c|}{53} \\
\hline
\end{tabular}

The first question of the survey related to the perception of air and water pollution by the city population. The survey results are presented in Table 3.

Thus, the greatest concern oa the citizens is the degree of air pollution; $51 \%$ of the respondents consider it to be high, and $27 \%$ as very high. Almost the same figures characterize the state of water in ponds: $49 \%$ of population believes the degree of its pollution to be high, $15 \%$ as very high. The respondents rate the condition of piped water as satisfactory. 
Table 3. Perception of the degree of air and water pollution (response rate, percent).

\begin{tabular}{|c|c|c|c|}
\hline Degree of pollution & Air & $\begin{array}{c}\text { Water in } \\
\text { ponds }\end{array}$ & Piped water \\
\hline Very high & 27 & 15 & 8 \\
\hline High & 51 & 49 & 20 \\
\hline Middle & 20 & 33 & 44 \\
\hline Below average & 2 & 3 & 21 \\
\hline Low & 0 & 0 & 7 \\
\hline
\end{tabular}

The next question aimed to identify the main sources of air emissions, which, according to the population, cause the greatest/least damage to environment status. The respondents were to rank the sources offered from the most harmful ( 1 place) to the least one $(5$ place). Table 4 demonstrates the results.

Table 4. Assessment of the contribution of various sources of pollutant emissions to the atmosphere of Kemerovo (response rate, percent).

\begin{tabular}{|c|c|c|c|c|c|}
\hline Source of emissions & 1 place & 2 place & 3 place & 4 place & 5 place \\
\hline Motor transport & 19 & 27 & 39 & 14 & 1 \\
\hline $\begin{array}{c}\text { Private sector } \\
\text { (heating) }\end{array}$ & 5 & 14 & 18 & 56 & 7 \\
\hline $\begin{array}{c}\text { Power generating } \\
\text { companies }\end{array}$ & 23 & 31 & 28 & 16 & 2 \\
\hline $\begin{array}{c}\text { Manufacturing } \\
\text { enterprises }\end{array}$ & 50 & 27 & 12 & 8 & 3 \\
\hline Other & - & - & - & 3 & 2 \\
\hline
\end{tabular}

The respondents were also asked to indicate their own option of other sources of air emissions. The vast majority of survey participants $(95 \%)$ did not indicate anything. Polluting sources mentioned were as follow: forest fires (3\% of the respondents), landfill deposits $(1 \%)$, smoking (1\%). Some respondents ranked not all the sources offered, believing that some of them do not harm the environment.

So, according to the majority of Kemerovo residents, manufacturing enterprises have the greatest harmful effect on the city atmosphere $-50 \%$ of the respondents put them in first place, and $27 \%$ - in the second. Power generating companies are ranked \#2, motor transport takes the third position, and, finally, the fourth position goes to private sector (heating).

The next question dealt with the effect of meteorological conditions (wind, fog, temperature) and landscape features (location in a basin along the river bed) on the air pollution. The results of the responses are presented in Figure 1. As one can see from the figure, meteorological conditions have greater impact on environment status than landscape features.

Further, the respondents were asked to name some enterprises that, in their opinion, have the greatest impact on the environment status, mentioning them in decreasing order of impact. The distribution of responses is presented in Table 5.

So, we can conclude that the vast majority of city residents consider AO SDS Azot as the most active air pollutant. According to the respondents, PAO Koks and OOO Khimprom also play a significant role in air pollution; power generating enterprises are in the fourth and fifth place in terms of the number of references. 


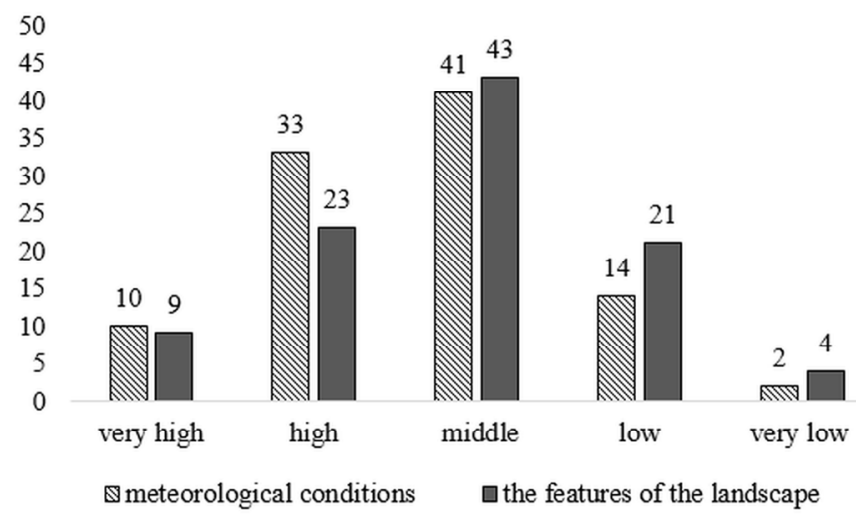

Fig. 1. Assessment of the degree of meteorological conditions and landscape features influence on air pollution (response rate, percent).

Table 5. Enterprises with the greatest environmental impact

\begin{tabular}{|l|c|c|}
\hline \multicolumn{1}{|c|}{ Name of enterprise } & $\begin{array}{c}\text { Share of } \\
\text { references in } \\
\text { total, } \%\end{array}$ & $\begin{array}{c}\text { Share of } \\
\text { references in } \\
\mathbf{1}^{\text {st }} \text { place, } \%\end{array}$ \\
\hline AO SDS Azot & 80 & 49 \\
\hline PAO Koks & 53 & 14 \\
\hline OOO Khimprom & 36 & 5 \\
\hline Kemerovskaya gidroelektrostantsiya* & 29 & 9 \\
\hline $\begin{array}{l}\text { Kemerovskaya teploelektrostantsiya, } \\
\text { Novokemerovskaya teploelektrostantsiya* }\end{array}$ & 23 & 3 \\
\hline OOO PO Tokem & 7 & 1 \\
\hline AO UK Kuzbassrazrezugol & 2 & 1 \\
\hline OOO PO Progress & 4 & 0 \\
\hline
\end{tabular}

* Kemerovo Hydroelectric Power Plant, New Kemerovo Combined Heat and Power Station, and New Kemerovo Combined Heat and Power Station are part of OOO Siberian Generating Company

During the survey, the respondents were also asked to assess the dynamics of the environmental situation in Kemerovo. $65 \%$ of them believes that the environment status has worsened, $32 \%$ - remained at the same level, and only 3\% reports improvement. Thus, the majority of Kemerovo citizens assume the city environment status deteriorating.

The last question aimed at identifying the degree of the respondents' personal concern. The degree of personal concern was rated as very high by $25 \%$ of residents, high $-42 \%$, medium $-2 \%$, below average $-4 \%$, low $-2 \%$. The results obtained indicate a serious concern of the city population with the environment status.

\section{Conclusion}

Comparing the survey results with the official sources, the following conclusions can be drawn:

- Official sources of information (the Federal State Statistics Service, Kemerovo Regional Office) and the population of Kemerovo state a high degree of air pollution in the city and a satisfactory water condition. 
- The opinion of the city citizens about the sources of emissions into the environment did not coincide with the information provided by the Deputy Governor of Kuzbass for Industry, Transport and Ecology. The citizens believe that manufacturing enterprises do the most harm to the atmosphere with AO SDS Azot being in the first place as an air pollutant. The official source of information states that the largest amount of air emissions comes from motor transport, while AO SDS Azot is in third place in terms of emissions.

- According to Kemerovo citizens meteorological conditions have a greater influence on the state of atmospheric air than landscape features. While the Deputy Governor believes that the city is "a hostage to its geographical position".

- The overwhelming majority of Kemerovo residents believe the environment status deteriorating. However, the official data indicate a decrease in emissions of some groups of pollutants while increasing emissions of others, which does not allow us to draw unambiguous conclusions about the actual deterioration of the environment state.

A comparison of the survey data and the data of the official sources leads to the main conclusion that the estimates of citizens do not fully coincide with statistic figures. There is a certain misperception of the environment status. In conditions of high concern, this situation may become critical. Thus, we would recommend the City Administration, the Public Ecological Council and leading enterprises that cause the greatest damage to the environment status to develop and implement a number of measures to work with the population, namely:

- Involving public activists and volunteers in the activity of the Public Ecological Council with the goal of both improving the environment status and shaping its real perception by the city residents.

- Timely and complete informing the population about the real dynamics of the ecological situation by regularly covering this information in the media (stories in regional news, publications in the press and on leading news portals on the Internet and social networks).

- Organizing Helplines allowing both to receive timely information from the population, and relieve social tension through outreach.

\section{References}

1. V.G. Mikhailov, A.G. Koryakov, G.S. Mikhailov, Journal of Mining Science, 51, 930$936(2015)$

2. Yu. Manakov, A. Kupriyanov, E3S Web of Conferences, 41, 02006 (2018)

3. T. Gvozdkova, M. Tyulenev, S. Zhironkin, V.A. Trifonov, Yu.M. Osipov, IOP Conf. Ser.: Earth Environ. Sci., 50, 012010 (2017)

4. A.B. Efremenkov, A.A. Khoreshok, S. Zhironkin, A.V. Myaskov, IOP Conf. Ser.: Earth Environ. Sci., 50, 012009 (2017)

5. I. Kudryashova, M. Venger, N. Zakharova, E3S Web of Conferences, 105, 02005 (2019)

6. E. Morozova, A. Akulov, T. Logunov, E3S Web of Conferences, 105, 02003 (2019)

7. L. Domaracká, M. Torres, N. Fonseca, A. Sokolova, M. Yazevich, E3S Web of Conferences, 41, 02018 (2018)

8. O. Safargalieva, O. Sergeev, Yu. Volgin, M. Agienko, E3S Web of Conferences, 105, 02012 (2019)

9. R. Drapezo, V. Shelestukov, E3S Web of Conferences, 105, 02016 (2019) 
10. N. Egorova, N. Zaruba, T. Jurzina, V. Tumin, E3S Web of Conferences, 41, 02001 (2018)

11. L. Starikova, L. Sagdeeva, I. Trapeznikova, E3S Web of Conferences, 105, 02014 (2019)

12. A.V. Novichikhin, A.V. Shorokhova, Steel in Translation, 47, 456-462 (2017)

13. G. Chistyakova, A. Rolgayzer, E. Bondareva, I. Schlee, Web of Conferences, 105, 02024 (2019)

14. V.N. Oparin, V.P. Potapov, A.B. Logov, E.L. Schastlivtsev, N.I. Yukina, Journal of Mining Science, 52, 1011-1019 (2016)

15. V.N. Oparin, V.P. Potapov, O.L. Giniyatullina, A.A. Bykov, E.L. Schastlivtsev, Journal of Mining Science, 53, 945-953 (2017) 